\title{
Big Dragons on Small Islands: generality and particularity in science.
}

Review of Angela Potochnik's Idealization and the Aims of Science.

Adrian Currie

Penultimate version, forthcoming in Biology \& Philosophy.

\section{Abstract}

Angela Potochnik's Idealization and the Aims of Science (Chicago) defends an ambitious and systematic account of scientific knowledge: ultimately science pursues human understanding rather than truth. Potochnik argues that idealization is rampant and unchecked in science. Further, given that idealizations involve departures from truth, this suggests science is not primarily about truth. I explore the relationship between truths about causal patterns and scientific understanding in light of this, and suggest that Potochnik underestimates the importance and power of highly particular narrative explanations.

Acknowledgements: thanks to Kirsten Walsh and Angela Potochnik for helpful comments on an early draft.

\section{Understanding Komodo Dragons.}

Komodo dragons are surprising. What is the world's largest lizard-adult males reaching 70 kilograms-doing on a scattering of Indonesian islands? Shouldn't big critters require big space? Not necessarily. Consider three properties. Whether animals are carnivorous or herbivorous; whether their metabolism rolls endothermic or ectothermic; the size of their range. Each property makes a difference to maximum size. Herbivores have more to eat, so the biggest herbivore should be larger than the biggest carnivore. Endothermy is more expensive than ectothermy, so if the largest animal is an ectotherm, it will be larger than if it were an endotherm. Smaller landmasses are resourcepoor, so the largest critter on a big island will be larger than the biggest critter on a small island.

Back in 2001, Burness, Diamond \& Flannery built an empirical model using these features. They surveyed islands and continents boasting reasonable fossil records, noting the largest herbivore and carnivore, taxonomic affiliation (a proxy for thermoregulation) and landmass size. To avoid noise from the Pleistocene megafaunal extinction, they looked no later than 65,000 years. Some distinctive patterns are detected (see fig 1 ). Most relevant to us: tracking body mass against land area, we find a size distribution predicted by our original three thoughts. Endotherm herbivores are largest, then ectotherm carnivores, then endotherm carnivores.

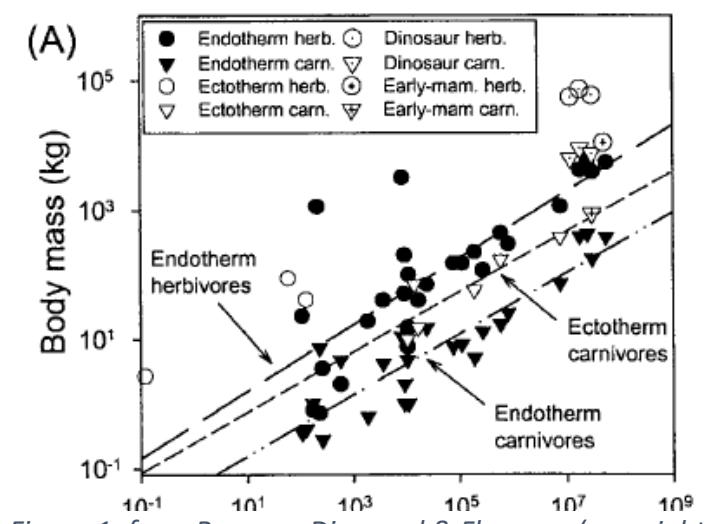

Figure 1: from Burness, Diamond \& Flannery (copyright 2001

National Academy of sciences) 
Thus, maximal body size can be modelled as a function of thermoregulation, land area, and trophic level. This provides insight into our dragons:

Flores formerly supported as its top herbivore a small elephant-like stegodont... [our model] shows Flores' area to be capable of supporting an endothermic top carnivore of only about 5 $\mathrm{kg}$, no match for a stegodont. Instead, Flores supports the Komodo dragon... despite its large size, the Komodo dragon has been able to maintain a viable population on Flores because of its low metabolic rate. Because more energy is available to lower trophic levels, Flores (and other islands with ectothermic top carnivores) can support large endothermic herbivores on which those carnivores prey. (14521)

Komodo Dragons aren't surprising after all: given their ectothermy and adaptation to preying on large endothermic herbivores, gigantism is expected. Such explanations are psychologically satisfying: the otherwise intractable complexity of the world-the ins and outs of Komodo-dragon life histories, behaviours, and evolutionary trajectories-is simplified to a graspable, human level. This strategy pervades science. The natural world is chock-a-block with complex, startling patterns, confounding human understanding. In response, scientists simplify matters: they idealize, abstract; distort nature to make it amenable to us.

This thought - that science makes the world's complexity accessible to human understanding via idealization-is the central contention of Angela Potochnik's ambitious, striking book Idealization and the Aims of Science. And this thought has far-reaching consequences for our conception of the nature of science: Potochnik argues that idealization is more pervasive than philosophers have hitherto realized, that scientists chase human understanding, not truth, and that this underwrites how we should approach explanation, science's structure, and the relationship between philosophy and science.

Potochnik provides a remarkably cohesive view of science generally speaking. She thus bucks philosophy of science's recent localist trend, but doesn't forget its lessons: for Potochnik, philosophy must understand science as a limited, human practice. Furthermore, the book is bold-it sticks its neck out - and this boldness is productive and laudable. At the same time, at their heart, Potochnik's views are extremely plausible. In this review, I'm interested in how Potochnik deals with the general, on one hand, and the particular, on the other. First-focusing on the general-l'll explore the important role that truth still plays in Potochnik's view. Second-the particular-l'll suggest that narrative explanations fit uncomfortably into her account. To begin, let's summarize the book.

\section{Potochnik on Idealization, Truth \& Understanding}

As we've seen, Potochnik's book is ambitious: it presents a systematic account of scientific knowledge, claiming that science is ultimately in the business of making the messy complexity of the world understandable to limited agents like us.

Several threads in the philosophy of science come together here. First, a commitment to scientific disunity and explanatory pluralism. Second, a focus on the role of idealization. Third, consideration of epistemic virtues and values beyond confirmation or verisimilitude. Burness, Diamond and Flannery's explanation of Komodo dragons is not necessarily in tension with explanations which, say, trace the evolutionary developmental trajectory which lead to their gigantism; and the various distortions and omissions characteristic of those different explanations serve to mark out their relative domains. It is common for us philosophers of science to think that different investigative interests bring local evidential and explanatory practices, and indeed set their success conditions (Wylie 1999, Sterelny 1996, Potochnik 2010); that distortion, idealization and abstraction play crucial 
roles in those practices (Wimsatt 2007, Weisberg 2012, Morrison \& Morgan 1999, Mitchell 2002); and that science isn't just in the truth-generating business (De Regt, Leonell \& Eigner 2009).

Potochnik synthesizes these threads, but goes further in two senses. First, the systematicity of the position; second, taking a commitment to pluralism and idealization vis-à-vis scientific aims much more seriously. Where idealization is often cordoned off into scientific models, Potochnik argues that it is rampant in science: that is, idealization is not simply a feature of models, but a feature of scientific practices and products generally. What does science do? For Potochnik what science does is idealize. Further, scientists are unapologetic about this: they are unconcerned about such rampant falsehoods; idealization is unchecked. And indeed, Burness, Diamond and Flannery treat the idealized features of their model as a feature not a bug:

[O]ne can think of other factors likely to perturb these predictions [about maximal size], such as environmental productivity, overwater dispersal, evolutionary times required for body size changes, and changing landmass area with geological time. Indeed, our database does suggest effects of these other actors. We propose our three predictions not because we expect them always to be correct, but because we expect them to describe broad patterns that must be understood in order to be able to detect and interpret deviations from those patterns. (Burness, Diamond \& Flannery 2001, 1458)

If such claims are characteristic of scientists, then either they are weirdly perverse, or this rampant idealization is crucial for the scientific project. But if idealization sacrifices truth, then perhaps science isn't searching for truth after all; and indeed, if idealization is merely an unhappy necessity, why are scientists unapologetic about it? And so, Potochnik claims, science does not target truth.

I want to mark an objection before continuing. Potochnik conceives of idealizations as "... assumptions made without regard for whether they are true and often with knowledge that they are false" (18). This differs from accounts which tend to split apart rather than lump together various non-truth-concerning assumptions. Consider, for instance, the distinction between the merely abstract and the truly idealized (Levy 2018, Norton 2012). An increasingly familiar articulation of idealization is as distortion. This is in contrast to abstraction which is taken to be mere omission. To idealize in this sense, Burness, Diamond \& Flannery need to do more than simply leave things out (simply not mention, for instance, paleogeographic changes in island-size) but must actively misrepresent things. When discussing idealizations in this strict sense, philosophers typically rehearse a small set of archetypical examples - infinite populations, frictionless planes, etc... But it is unclear to me whether these kinds of idealization are truly rampant in science. Is, for instance, Burness, Diamond \& Flannery's model an example of a distortion, does it actively misrepresent their target, or is it merely omission: are some parts just left out?

I think this is a subtle issue. Consider Potochnik on game theoretic explanations of cooperation:

A number of idealizations are required, assumptions that are false of many or all target systems. These idealizations include the assumption that reproduction is asexual and that population size is infinite... They also include the assumption that the fitness effects of traits are constant across individuals and circumstances... (64)

Representing a sexual population as if it were asexual looks like an idealization-sexual reproduction isn't simply omitted. But assuming that fitness effects are constant is more like an abstraction: we're assuming a kind of average fitness in a population and ignoring individual variation. This matters because Potochnik is a fictionalist about scientific idealizations: on her view, scientific idealizations represent the world as if it has features which it doesn't actually have; the representations are false. 
Fictionalism looks plausible for idealizations, but less so for abstractions. If Potochnik takes idealization in her broad sense, then it is unclear whether we should agree that 'idealizations' are typically false; if she takes a narrower view, then we might doubt whether idealization is rampant.

For now, let's grant that scientists ubiquitously employ false, distorting representations, and thus do not pursue truth. What do they chase instead? According to Potochnik, they chase understanding.

Potochnik's account of understanding is grounded in Catherine Elgin's. For Elgin, understanding has a dual nature (Elgin 2017, Elgin 2007). It is a cognitive state, and so is subject to the properties of the knower. It is also an epistemic achievement and, as such, is tied to the success conditions for that achievement. One crucial success condition is being true enough given the argument, theory or explanation in which it is employed. Following Elgin, Potochnik argues that scientists don't believe false claims, they instead adopt non-doxastic epistemic attitudes towards idealizations given the investigative purpose at hand; that is, given standards of epistemic acceptance.

Assuming for the moment that Burness, Diamond \& Flannery have succeeded in generating understanding, let's flesh out Potochnik's account. It is strictly-speaking false that maximal size is a function of island size, thermoregulation, and ecological niche, but nonetheless it is approximately right - true enough-for the purpose of accounting for the differences in maximal size across carnivorous and herbivorous megafauna. For Komodo dragons, we may point to the low-cost reptilian thermoregulative system in explaining why Flores' top predator isn't a mammal. And, again assuming success, the explanation is simple enough to generate the relevant cognitive states in us qua human agents. The vagaries of a lineage's evolutionary history is perhaps mindboggling, and the actual fine-grained details of the ins and outs of thermoregulation might be beyond me, but that warm-blooded critters need more fuel than cold-blooded critters, and so cold-blooded critters can manage bigger sizes with less fuel, I can readily grasp. As such, we adopt an attitude of epistemic acceptance towards the idealization, in light of its capacity to generate idealized representations of particular instances in the world which we can understand.

There is a final piece to the puzzle here: an ontological one. For Potochnik, the world isn't only complex, but characterized by a plurality of causal patterns. That is, the natural world involves (1) patterns, e.g. recurrent regularities embodied in phenomena such as how Komodo dragons are large ectothermic carnivores occupying small islands, that are (2) causal, e.g. there are dependence relations between being an ectothermic carnivore and attaining large sizes on small islands. These patterns often cross-cut, and phenomena embody a multitude of them. With Dennett (1991), Potochnik is a realist about these patterns. And this is what enables her to connect scientific fictions-representing 'as if' - with the world: scientific fictions represent the real patterns which phenomena embody.

Scientists, when they do their jobs right, develop representations of patterns in the world. Because any particular phenomenon doesn't embody any particular pattern perfectly, idealization is required to bring out the pattern. Idealization, therefore, doesn't just take away; it adds. As such, for Potochnik idealization plays a positive role in representation to the end of generating understanding. "[I]dealizations are used to set aside complicating factors to help scientists discern the causal patterns they are primarily interested in. The neglected complicating factors might well be significant causal influences in their own right, insignificant only to the focal pattern" (47). Science succeeds in producing understanding of phenomena when idealizations succeed in identifying the causal patterns relevant to our explanatory interests. This thought grounds Potochnik's pluralism. 
Komodo dragons are taken to be island giants: their smaller, lizardy ancestors arrived on the islands and adapted to circumstance by, over evolutionary time, being fitted to the niche Burness, Diamond and Flannery describe. A competing explanation takes them to be relics: the survivors of a once wide-spread population of enormous varanid lizards. Hocknull and colleagues (2009) point to the 10 meter long monitor lizards which dominated Australia's Pleistocene and, via reconstruction of their evolutionary distribution, argue that the ancestral population were Australian giants. Here then are two competing patterns: island gigantism versus relic. It is sensible to ask which of these inconsistent patterns is real. However, we shouldn't take Burness, Diamond \& Flannery's work to be in conflict with either of these potential casual patterns. Consider again what they have to say about Flores: "Despite its large size, the Komodo dragon has been able to maintain a viable population on Flores because of its low metabolic rate" (14521). This is not a claim about which evolutionary route the lineage took in arriving on Flores. Rather, it explains how the island manages to support them. This leaves questions of phylogeny and radiation-how they came to be on the island-open.

How scientists carve up the world is intimately connected with their explanatory interests. Komodo dragons embody a multitude of causal patterns: some concerning patterns of evolutionary radiation, others ecological relationships between thermoregulative systems and viable population size. Which pattern is salient depends on the question being asked, and so apparent disagreements often turn out not to be so: "different interpretations transform what may otherwise appear to be a crisis or at least limitation of an investigation into an expected feature of successful scientific research" (110).

To summarize, then, for Potochnik idealization has a positive function-highlighting the relevant-toour-interests causal pattern embodied in phenomena-and its being rampant and unchecked tells us that truth is not science's main aim. Instead, she argues that science's ultimate aim is understanding: that is, being just true enough to be epistemically acceptable, while ticking the boxes necessitated by our status as limited epistemic agents.

Chapters 1-4 busy themselves articulating and defending these theses, which Potochnik then wields to hit big targets in the philosophy of science. Chapter 5 considers explanation arguing (rightly, in my view) for a communicative rather than ontic conception, and building a novel account (which l'll discuss later). In chapter 6 , Potochnik deftly deflates the notion that scientific fields or theories come in metaphysical or epistemic hierarchies, in its stead revisiting her Neurathian conception of scientific unity (Potochnik 2011). Chapter 7 includes three broad strokes. She connects her view with values in science; she takes a broadside at the 'scientific metaphysics' of, say, Dupré (1995) or Ladyman and Ross (2007), by arguing (I think convincingly) that "One cannot in general simply read metaphysical implications directly off scientific findings" (212); and finally she reigns in her pluralism to defend a modest scientific realism. This is a rich book with a lot to unpack; I'm going to first dig into how Potochnik thinks about scientific generalities, and then switch to the particular.

\section{The General}

I presented Burness, Diamond \& Flannery as if their model's aim was explaining the otherwise mysterious existence of Komodo dragons. But this is only one way of reading the situation, and switching our focus can emphasize the critical role truth still plays in Potochnik's view. In this section, then, I'll consider a pattern-focused account of the truth scientists are after and, following from this, suggest an account of scientific understanding which, I think, Potochnik should find amenable.

In what sense are models 'strictly speaking' untrue? Recall the role they play for Potochnik: 
An idealization asserts the nature of a factor's relevance by saying something false about that factor - by representing it as if it were some way it wasn't. In doing so, idealizations are fulfilling a subtle, but positive, representative purpose (52).

Idealizations isolate the causal patterns embodied in a phenomenon relevant for its explanation. As we see in her discussion of evolutionary models of cooperation:

... the main goal is not to generate accurate predictions or to accurately represent systems but to create partial, skewed representations. This partialness and skewing furthers the depiction of patterns in the causal role of [in this case] natural selection (70).

Because no individual case perfectly instantiates a causal pattern, and causal patterns are necessary for explanation and understanding, scientific representations are never perfectly true (although of course Potochnik doesn't deny that some scientific investigations aim for accurate prediction). I take Potochnik to embrace a correspondence theory of truth, wherein truth basically aligns with accuracy. I'm not particularly attracted to this, but will go along with it here. In addition to assuming that truth = accuracy, Potochnik highlights the inaccuracy of particular explanations: that is how she gets to the claim that much of science is strictly-speaking false. However, Potochnik does, I think, believe there are truths about causal patterns themselves (she is, after all, a realist about them)might these be the truths that scientists are ultimately after? Consider the following claim from Burness, Diamond \& Flannery:

Larger home ranges translate into lower population densities, hence lower population sizes (number of individuals constituting a population) for a given area. (14521)

On a Potochnik-style reading this claim is approximately true of phenomena because in many particular instances it roughly captures what's going on (because those instances imperfectly embody the causal pattern at hand). Additionally, I think we can say the statement is simply true. It is true of the causal pattern. In the good case it is as accurate as the correspondence theorist could want. The referent of the proposition is not particular populations, but the causal patterns which those populations instantiate. One reason for liking this approach is that it follows scientific linguistic behaviour: I reckon general statements are carefully hedged when applied to particular cases, but otherwise boldly stated as we in the quote above. On this view, scientists say an awful lot that is true about patterns (even if, as Potochnik says, they do not say much strictly true of phenomena). But what about understanding on such a view? Before answering that, I want to hit two quick objections.

First, consider those pesky impossible idealizations: idealizations in a strict sense. As Potochnik says, "no biologist actually believes she is dealing with an infinite population of organisms" (96). I think this is likely right, but it doesn't follow that biologists don't believe that, for instance, natural selection drives fit traits to fixation across generations - another reading of the model's content. And indeed the point of positing infinite populations is to control for drift, and thus capture causal patterns concerning natural selection and fitness. To ascertain whether scientific representations are true or false-if that is the appropriate framing-we need to ascertain what their content is. For Potochnik to say that ideal posits such as 'infinite population size' are false, then I take it we require (1) truth-apt content about (2) infinite populations. There are ways of avoiding such commitments: scientists might not in fact posit infinite populations at all, or that content might not be properlyspeaking truth-apt. At any rate, debate on similar issues in the philosophy of modelling is sufficient to show this is a tricky-and open-question ${ }^{1}$.

\footnotetext{
${ }^{1}$ See, for instance, debates between structuralists and fictionalists about modelling (e.g., Weisberg 2012).
} 
Second, what about spooky metaphysics? According to correspondence theories, sentences are true or false in virtue of their relationship with the objects to which they refer. If I (and Potochnik hopefully) think scientists say true things of objects which are only partially instantiated, are we committed to a kind of (thunderclap) Platonism? Well, perhaps and maybe: I think both metaphysics and questions of reference and truth are much subtler than we philosophers of science often give them credit for, and suspect that what I've sketched easily underdetermines a range of views on the nature of objects, reference and truth. Now, to understanding.

Potochnik's understanding looks propositional to me: to understand is to have knowledge of relevant causal patterns, given (1) the phenomena at hand and (2) the kinds of cognitive agents we are, particularly our interests. We understand just when the target phenomenon sufficiently embodies the causal pattern which can be used to answer our question.

There is a richer way of thinking about understanding, which is highlighted by this shift in focus from the particular to the general. My knowing the details of Burness, Diamond \& Flannery's model is not, I think, sufficient for my understanding it. In addition to their telling me about the model's components and the ideas underwriting its conception, they also demonstrate how to deploy the model in explaining maximal size across lineages. That is, I don't simply know that, for instance, endotherms require more resources than ectotherms, but I have (certainly partial in my case) knowhow regarding how that knowledge may be employed to situate komodo dragons (and other cases) within a comparative or modal space (see Le Behain 2016 for one way this could go). It is this knowhow which partly constitutes the understanding generated by the model ${ }^{2}$.

And so agreeing with Potochnik that idealization is rampant and unchecked does not commit us to seeing truth as scientifically secondary. Science aims for truths concerning causal patterns. Secondarily to this, the application of causal patterns to particular instances constitutes a kind of know-how which we could call understanding.

\section{The Particular}

In the last section, I explored the general-causal patterns-in this section, I'll do the opposite: the particular. My discussion is focused on Potochnik's account of explanation.

Potochnik roots explanation in causal patterns, which are (let's remind ourselves): "regularities embodied by some range of phenomena, where the regularities permit deviations and exceptions and the range of phenomena is limited" (136). Roughly speaking, a successful explanation of a phenomenon cites the causal pattern that it embodies which is sufficient given our explanatory interests. This account of explanation is primarily causal: we situate an explanandum 'in the nexus of the world' (Salmon 1989). However, its appeal to casual patterns also incorporates aspects of unificatory accounts of explanation: drawing the explanandum and similar cases together generates explanatory power.

Causal pattern explanations thus identify not just features of the phenomena to be explained but also of a general class of relevantly similar phenomena (possible or actual)...

\footnotetext{
${ }^{2}$ You might worry that this relies on arcane questions concerning the relationship between know-how and know-that: if ultimately know-how may be collapsed into know-that-if all knowledge is ultimately propositional-does this undermine the difference? And is the view beholden to that debate? I don't think so. Potochnik is interested in science as conducted by limited human agents and, as such, whether or not abilities are ultimately just sets of propositions is irrelevant.
} 
Explaining with causal patterns renders phenomena expectable in virtue of providing insight into a general pattern of manipubility relations across some range of circumstances (136)

There is much to like in Potochnik's account of explanation. One crucial aspect is attention to scope: the explanation's modal properties. Scientific explanations don't just tell us about such-and-such's causal history-about the dependency relationships that led to its occurrence-but situates the event within a modal space. However, I suspect this doesn't capture a set of explanations (unfairly maligned in some quarters): narrative explanations.

We've heard one kind of story about Komodo dragons: despite their size, they survive on Flores because of the relationship between their thermoregulative system and other causal structures. Here, the particular is understood in terms of the general; Potochnik's account of explanation fits nicely. Indeed, she provides a similar example regarding the role of declining Dingo numbers in explaining mammal extinctions in Australia (p138). But there are other kinds of stories about Komodo dragons. That lineage is the product of a complex array of causal factors spread across time. Such a story involves the radiation of large monitor lizards out of Australia, the various biogeographical changes involved in populating islands like Flores, the whatever-set-ofhappenstances which underwrote the Pleistocene megafaunal extinctions which left the dragons taxonomic orphans, and the particular features of the islands which provided safe haven. Philosophers interested in this latter kind of narrative often emphasize the apparent uniqueness of historical targets: instead of taking one's explanandum as a token of a causal-pattern type, we trace its distinctive trajectory (see, for instance Currie 2014, Beatty 2017). Given Potochnik's focus on causal patterns, the peculiarity of narratives are a challenge

In such narrative explanations, no single causal pattern is highlighted. Rather, a whole series of such patterns (Pleistocene extinction, biogeographical changes, and so on) are knitted together. For David Hull, where law-based explanations gain their explanatory unity - their power-via laws, narratives owe their explanatory prowess to central subjects, the thing which the narrative is about (Hull 1975, 1989). "The role of the central subject is to form the main strand around which the historical narrative is woven" (255). That is, it is the unique causal history of the Komodo dragon which provides the explanation's unity.

Potochnik emphasizes the unity that comes from causal patterns, but in narrative cases causal patterns are not unifying. I suspect that in such cases causal patterns don't add to the explanatory power of the explanation, rather, they add evidential power: that is, the causal pattern gives us more reason to think the explanation is true ${ }^{3}$. It is the causal trajectory which makes sense of the central subject that is explanatorily powerful.

Note the inversion here: where for Potochnik our having a particular question about a phenomenon is answered via a representation of a causal pattern that the phenomenon embodies; we here appeal to the structure of the phenomenon to explain why it embodies the causal patterns that it does. It is because of the history and causal connections between and within the Komodo dragon lineage's history that we are able to apply the models that we do. So, in the first kind of explanation, causal patterns-regularities - carry the explanatory load; in the second, it is the particular phenomenon, the features that explain its causal continuity across time, that carry the explanatory load (and thus the understanding). Of course, in providing epistemic warrant for claims concerning

\footnotetext{
${ }^{3}$ Such narratives are themselves at least as incomplete as other scientific explanations: a history which recounts the history of each particle is a terrible history, at least for limited agents such as ourselves. As such, a historical narrative-just like a causal pattern -is indexed to our explanatory interests. However because they are not recurrent I think they shouldn't be considered 'causal patterns' in Potochnik's sense.
} 
the continuity, trajectory and evolution of our target we may appeal to regularities-to similarities between that causal pattern and some other. But they do not provision the understanding or the explanation: the narrative does.

Potochnik briefly considers what she calls 'integrated explanations' which approach the kind of narratives I've highlighted. She would take such explanations to be targeting highly specific patterns-but patterns nonetheless. However, because they lose generality, "I expect integrated explanations will be pursued only in special circumstances, in virtue of the expense of developing them and their focus on causal patterns with restricted scope" (152). There are two problems with this. First, such explanations are common: provisioning highly local, focused explanations are not the only thing that scientists do, but it is an important aspect of much scientific work (Morgan \& Wise 2017). Moreover, such narratives are epistemically respectable (Currie \& Sterelny 2017). Second, narrative explanations don't lose explanatory power by being local. Rather, they gain power in virtue of providing an integrated causal history-picking out a central subject-and this can generate rich understanding indeed.

\section{Conclusion}

Potochnik gives us much to think about. She walks two tightropes with grace: between a general account of what science is like, while keeping true to science's idiosyncrasies; between taking science's epistemic constraints seriously, while not collapsing into pessimism, unable to account for science's undoubted success. I haven't said much concerning this last point, but I think it is an important lesson. Science doesn't succeed in spite of human foibles and the world's complexity; science succeeds by bridging the two. That is, for Potochnik science is "responsive to and reflective of human particularities-but in ways that contribute to, rather than undermine, science's success" (199).

\section{Bibliography.}

Beatty, J. (2017). Narrative possibility and narrative explanation. Studies in History and Philosophy of Science Part A, 62, 31-41.

Burness, G. P., Diamond, J., \& Flannery, T. (2001). Dinosaurs, dragons, and dwarfs: the evolution of maximal body size. Proceedings of the National Academy of Sciences, 98(25), 14518-14523.

Currie, A., \& Sterelny, K. (2017). In defence of story-telling. Studies in History and Philosophy of Science Part A, 62, 14-21.

Currie, A. M. (2014). Narratives, mechanisms and progress in historical science. Synthese, 191(6), 1163-1183.

De Regt, H. W., Leonelli, S., \& Eigner, K. (Eds.). (2009). Scientific understanding: Philosophical perspectives. University of Pittsburgh Press.

Dennett, D. C. (1991). Real patterns. The journal of Philosophy, 88(1), 27-51.

Dupré, J. (1995). The disorder of things: Metaphysical foundations of the disunity of science. Harvard University Press.

Elgin, C. Z. (2017). True enough. MIT Press.

Elgin, C. (2007). Understanding and the facts. Philosophical Studies, 132(1), 33-42. 
Hocknull, S. A., Piper, P. J., van den Bergh, G. D., Due, R. A., Morwood, M. J., \& Kurniawan, I. (2009). Dragon's paradise lost: palaeobiogeography, evolution and extinction of the largest-ever terrestrial lizards (Varanidae). PLoS One, 4(9), e7241.

Hull, D. L. (1975). Central Subjects and Historical Narratives. History and Theory 14(3): 253-274.

Hull, D. L. (1989). The metaphysics of evolution. Albany, State University of New York Press.

Ladyman, J., Ross, D., (2007). Every thing must go: Metaphysics naturalized. Oxford University Press.

Le Bihan, S. (2016). Enlightening Falsehoods. Explaining Understanding: New Perspectives from Epistemology and Philosophy of Science. Grimm, S. R., Baumberger, C., \& Ammon, S. (Eds.). Routledge, pp $111-135$

Levy, A. (2018). Idealization and abstraction: refining the distinction. Synthese, 1-18.

Mitchell, S. D. (2003). Biological complexity and integrative pluralism. Cambridge University Press.

Morgan, M. S \& Wise, N (2017). Narrative science and narrative knowing. Introduction to special issue on narrative science. Studies in History and Philosophy of Science Part A, 62, 1-5.

Morrison, Margaret \& Morgan, Mary (eds.) (1999). Models as Mediators. Cambridge University Press.

Norton, J. D. (2012). Approximation and idealization: Why the difference matters. Philosophy of Science, 79 , 207-232.

Potochnik, A. (2017). Idealization and the Aims of Science. University of Chicago Press.

Potochnik, A. (2010). Explanatory independence and epistemic interdependence: A case study of the optimality approach. The British Journal for the Philosophy of Science, 61(1), 213-233.

Potochnik, A. (2011). A neurathian conception of the unity of science. Erkenntnis, 74(3), 305-319.

Salmon, W. (1989). Four decades of scientific explanation. University of Pittsburg Press.

Sterelny, K. (1996). Explanatory pluralism in evolutionary biology. Biology \& Philosophy, 11(2), 193214.

Wimsatt, W. C. (2007). Re-engineering philosophy for limited beings: Piecewise approximations to reality. Harvard University Press.

Wylie A (1999) Rethinking unity as a "working hypothesis" for philosophy of science: how archaeologists exploit the disunities of science. Perspect Sci 7(3):293-317 